time infection control nurses; and they may be too few in number in relation to the size of the hospital.

Pathogens that have been reported as causing nosocomial infections in these African countries are quite different from those in developed countries. They include bacteria such as Salmonella, ${ }^{3}$ Shigella, Vibrio, Mycobacterium, and Lassa fever virus. In smaller hospitals there may be no microbiological laboratory support at all. Even where laboratories are available and functioning, investigation of infection is severely hampered due to lack of equipment, materials, and properly trained technicians.

Resistant strains of pathogenic species have been reported in most African countries. ${ }^{4}$ Misuse of antimicrobial agents is very common in Africa; drugs are easily available over the counter or even in open-air markets. Even in hospitals, there may be inappropriate use of antimicrobials, especially for prophylaxis.

Another major problem is the attitude of hospital administrators to infection control. In an area of lack of resources, it may seem to administrators that providing the needed finances for infection control measures will increase costs. However, the relative lack of resources should not be used as an excuse for doing nothing. Fairly simple things, such as the regular provision of soap and running water, can lead to marked changes in hospital infection rates.

Antibiotic use in hospitals and in the community needs to be controlled. Laboratory support should be provided for surveillance of antibiotic resistance. In developing countries, pharmacists are placed uniquely to help control the use of drugs, since they have contact with patients. ${ }^{5}$ They can be mobilized to serve as health promoters and educators, even though some of them create part of the problem by selling antibiotics without prescription.

It is now time for national action on infection control. Health ministers must set standards and enforce them by inspection at all levels of the health delivery system.

Surveillance of hospitals must be instituted so that the extent of the problem can be documented. Local surveillance reports could be used to create awareness of the extent of the problem at all levels of healthcare workers and also to convince hospital managers to allocate funds for control of hospital infection. If it is not possible to survey the whole healthcare facility, surveillance could be started in high-risk units.

The attitudes of administrators to hospital infection need to change. They must be given information about hospital infection so that they will be aware of the problems and see the value of allocating more resources for infection control.

If necessary, legislation must be passed that places the responsibility of safe care on hospital administrators. ${ }^{6}$ Legislation also is needed for the management of infectious waste.

In the training of young doctors and nurses, all aspects of infection control must be stressed in the syllabus. In addition, continuous education for all healthcare personnel must be done regularly. Countries with more resources and international organizations such as the World Health Organization can help with training and development of research programs and appropriate local guidelines in developing countries.

Finally, healthcare workers must be protected while working with infectious patients and contaminated materials. Since measures used in industrialized countries to control diseases such as tuberculosis in the healthcare setting are beyond the resources of developing countries, healthcare workers must be protected by using methods involving practical measures relating to diagnosis and treatment of infectious cases, appropriate environmental control, and relevant personal protection and surveillance. ${ }^{\text {? }}$

\section{REFERENCES}

1. World Health Organization. The least developed countries: a substantial new programme of action for $1980 \mathrm{~s}$. WHO Chronicle 1981;35:223-226.

2. Mayon-White RT, Ducel G, Kereselidze T, Tikomirov E. An international survey of the prevalence of hospital-acquired infection. $J$ Hosp Infect 1988;11 (suppl A):43-48.

3. Newman MJ. Multiple-resistant Salmonella group $\mathrm{G}$ outbreak in a neonatal intensive care unit. West Afr J Med 1996;15:165-169.

4. Kunin CM, Johansen KS, Worning AM, Daschner FD. Report of a symposium on use and abuse of antibiotics worldwide. Rev Infect Dis 1990;12:12-19.

5. Jayasuriya I)C. Let pharmacists do more for health in developing countries. World Health Forum 1994:15:403-405.

6 . Pearse J. The health care system and infection prevention issues in South Africa. Asepsis 1995;17:4-6.

7. Harries AD, Maher D, Nunn P. Practical and affordable measures for the protection of healthcare workers from tuberculosis in lowincome countries. Bull World Health Organ 1997;75:477-489.

Mercy J. Newman, MB, ChB University of Ghana Medical School Accra, Ghana, South Africa

\title{
Rodac Plate Method to Recover VRE From Environmental Surfaces
}

\begin{abstract}
Gina Pugliese, RN, MS Martin S. Favero, PhD
\end{abstract}

Hacek from the Northwestern Prevention EpiCenter, Northwestern Memorial Hospital and Northwestern University Medical School, Chicago, Illinois, compared the Rodac imprint technique to selective enrichment broth for detecting vancomycin-resistant enterococci (VRE) and multidrug-resistant Enterobacteriaceae (MDRE) on surfaces.
Rodac plates contained tryptic soy agar with $5 \%$ sheep blood, vancomycin (6 $\mu \mathrm{g} / \mathrm{mL})$, ceftazidime $(2 \mu \mathrm{g} / \mathrm{mL})$, amphotericin $\mathrm{B}(2 \mu \mathrm{g} / \mathrm{mL})$, and clindamycin (1 $\mu \mathrm{g} / \mathrm{mL}$ ). Two types of broth were used: brain heart infusion (BHI) and BHI plus vancomycin $(6 \mu \mathrm{g} / \mathrm{mL})$ and ceftazidime $(2 \mu \mathrm{g} / \mathrm{mL} ;$ BHIVC). Of the 46 surfaces cultured for VRE, 12 (26\%) were positive. Of the 12 VRE-positive surfaces, $11(92 \%)$ grew from Rodac, 8 (67\%) grew from BHIVC, and $7(58 \%)$ grew from BHI. A larger study is needed for MDRE, as only
4 of 43 surfaces were MDRE-positive. The Rodac imprint technique successfully recovered VRE from environmental surfaces.

FROM: Hacek DM, Trick WE, Collins SM, Noskin GA, Peterson LR. Comparison of the Rodac imprint method to selective enrichment broth for recovery of vancomycin-resistant enterococci and drug-resistant Enterobacteriaceae from environmental surfaces. J Clin Microbiol 2000;38:4646-4648. 